\title{
Gas-Phase Basicities of Histidine and Lysine and their Selected Di- and Tripeptides
}

\author{
Scott R. Carr and Carolyn J. Cassady \\ Department of Chemistry, Miami University, Oxford, Ohio, USA
}

\begin{abstract}
The gas-phase basicities (GB) of histidine, lysine, and di- and triglycyl peptides containing either one histidine or one lysine residue have been determined. In all, 12 compounds were examined in a Fourier transform ion cyclotron resonance mass spectrometer. The GBs of the biomolecules were evaluated by proton transfer reactions employing a range of reference compounds with varying gas-phase basicities. In addition, the GBs were determined by using the kinetic method of collision-induced dissociation on a proton-bound dimer containing the peptide and a reference compound. The GBs of histidine and lysine were both found to be $220.8 \mathrm{kcal} / \mathrm{mol}$ via proton transfer reactions. The kinetic method experiments, including dissociation of a proton-bound dimer containing both histidine and lysine, also suggest equivalent GBs for these amino acids. However, the small peptides containing lysine are generally more basic than the corresponding histidine-containing peptides. For the peptides, the data suggest that the protonation site is on the basic side chain functional group of the histidine or lysine residues. The GBs of the di- and tripeptides are dependent upon the location of the basic residue. For example, the GBs of the tripeptides glycylglycyl-L-lysine (GlyGlyLys) and L-lysylglycylglycine (LysGlyGly) were both determined to be $230.7 \mathrm{kcal} / \mathrm{mol}$ while a GB of $\mathrm{kcal} / \mathrm{mol}$ was obtained for glycyl-L-lysylglycine (GlyLysGly). A similar GB trend is seen with the histidine-containing tripeptides. Generally, the GBs obtained by using the kinetic method are slightly higher than those obtained by deprotonation reactions; however, the trends in relative GB values are essentially the same with the two techniques. (c) 1996 American Society for Mass Spectrometry (J Am Soc Mass Spectrom 1996, 7, 1203-1210)
\end{abstract}

$\mathrm{S}$ everal recent studies have measured the gas-phase basicities (GB, $-\Delta G$ of protonation) of amino acids and small peptides [1-9]. These values are of interest due to the importance of proton transfer reactions in biological systems [10]. The locations of the basic sites on peptides affect the hydrogen bonding in the biomolecule and therefore impact biological activity. Gas-phase basicity determinations are one way of gaining information on the protonation site of biomolecules. Our research probes the reactivity of amino acids and peptides in the gas phase to provide keys for understanding their intrinsic chemical properties in the absence of solvents.

In this study, proton transfer reactions of protonnated peptides with reference compounds have been used to determine the GBs of several high basicity amino acids and small peptides. The GBs of these biomolecules were also determined by the kinetic method [11-13] when proton-bound dimer formation was observed. The compounds studied are the amino acids histidine and lysine, as well as di- and tripep-

Address reprint requests to Dr. C. J. Cassady, Department of Chemistry, Miami University, Oxford, OH 45056. tides containing these residues and glycine. Of the common L- $\alpha$-amino acids, the three that possess the highest gas-phase basicity are arginine, histidine, and lysine. Arginine is without question the most basic with a GB of $240 \mathrm{kcal} / \mathrm{mol}$ [8], which is approximately $15 \mathrm{kcal} / \mathrm{mol}$ greater than the GBs of the next two most basic amino acids, histidine and lysine. There exists some uncertainty, however, in the ordering of the basicities of histidine and lysine (see Table 1). Several studies [2, 8, 14-17] indicate the GB of histidine is higher than the GB of lysine. Of these studies, one employed equilibrium measurements [14] while the others utilized the kinetic method $[2,8,15-17]$. Other studies, which used either proton transfer reactions of species laser-desorbed from solid amino acids [6] or semiempirical calculations [3] to determine GBs, suggest that lysine has a higher GB than histidine. This difference in GBs obtained by proton transfer reactions and the kinetic method has led Amster and co-workers [3] to suggest that intramolecular hydrogen bonding in lysine has yielded an erroneous GB by the kinetic method. In an attempt to shed light on this issue, our work utilizes both deprotonation reactions and kinetic method experiments to measure the GBs of histidine and lysine and their selected di- and tripeptides. For 
Table 1. Comparison of literature gas-phase basicities for histidine and lysine ${ }^{\mathrm{a}}$

\begin{tabular}{|c|c|c|c|}
\hline Reference & $\begin{array}{c}\text { Lysine } \\
\text { (kcal/mol) }\end{array}$ & $\begin{array}{c}\text { Histidine } \\
\text { (kcal/mol) }\end{array}$ & Method ${ }^{b}$ \\
\hline Lias $^{c}$ & 222.5 & 224.1 & Equilibrium \\
\hline Amster $^{d}$ & 218.7 & 213.1 & Deprotonation \\
\hline Fenselau ${ }^{e}$ & 224.3 & 224.8 & Kinetic \\
\hline Bojesen ${ }^{f}$ & 217.7 & 221.3 & Kinetic \\
\hline This work & 220.8 & 220.8 & Deprotonation \\
\hline This work & 223.2 & 223.2 & Kinetic \\
\hline
\end{tabular}

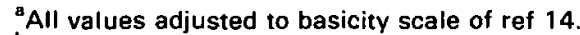

${ }^{\text {M }}$ Method refers to the experimental procedure used to obtain the GBs.

Obtained from ref 14

Obtained from ref 6 .

Obtained from ref 16

'Proton affinities obtained from ref 17 were converted to GBs using entropy terms from ref 16 .

both procedures, ions are produced by fast-atom bombardment (FAB) on biomolecules dissolved in a liquid matrix.

Each of these amino acids has a unique structural feature in comparison to the other, namely, the 4methyleneimidazolo group for histidine and the nbutylamino group for lysine. While one can delocalize excess charge in the imidazole ring (histidine), the other has a basic amine functionality on a short chain of reduced carbons (lysine) to inductively stabilize an additional proton. In addition, the side chains of these compounds may be able to form intramolecular hydrogen bonds at various sites. Semiempirical calculations performed on histidine and lysine indicate protonation on the side chain functional groups of the amino acids along with intramolecular hydrogen bonding [3]. Also, collision-induced dissociation (CID) studies on protonated peptides have suggested that the protonation site for histidine and lysine, as well as arginine, is on the $\alpha$-carbon functional groups of these basic residues [18-20].

In the present study, histidine and lysine are examined individually to determine the effects of the differing side chains on gas-phase basicity. In addition, their residues are substituted into di- and tripeptides of glycine to explore their impact on peptide basicity. A hydrogen is in effect systematically removed from a glycine di- or tripeptide "backbone" at an L- $\alpha$-carbon position and replaced by a 4-methyleneimidazolo or an $n$-butylamino group to form the various histidine or lysine peptides, respectively. This research provides information concerning the effect of sequence on the GBs of small peptides that contain a highly basic amino acid residue.

\section{Experimental Methods}

The experimental procedures have been described previously [4]. Briefly, all experiments were performed with a Bruker (Billerica, MA) CMS-47X Fourier transform ion cyclotron resonance mass spectrometer (FTICR). Protonated peptide ions were produced in an external source utilizing a Phrasor Scientific (Duarte, CA) FAB gun [21] employing a $6-10-\mathrm{kV}$ beam of xenon or argon atoms and ions. The ions were produced from saturated solutions of the peptides in a glycerol matrix which was doped with trifluoroacetic acid to increase protonated ion abundance.

Following ion transfer from the FAB source into the FT-ICR cell, collisional cooling of the peptide ions [22] was performed by using a pulsed pressure of argon to $\geq 10^{-5}$ torr and a $0.3-0.5$-s collision period. Resonant frequency ejection techniques [23] were employed to mass select the protonated peptide ions $\left(\mathrm{MH}^{+}\right)$without excitation of the ion of interest. Then $\mathrm{MH}^{+}$were allowed to react with the reference compounds present at a static pressure of $(1-22) \times 10^{-8}$ torr. The pseudofirst-order change in reactant ion intensity as a function of time at constant pressure was observed in order to determine the overall proton transfer rate constants. Where proton-bound dimer formation also occurred the rate constant for the protonation pathway was obtained from a plot of the relative protonated reference compound intensity as a function of time [24]. Pressures were measured with a calibrated ionization gauge [25]. Reported reaction efficiencies are the ratio of the experimental deprotonation rate constant to collision rate constant as calculated by using the thermal capture trajectory calculations procedure of $\mathrm{Su}$ and Chesnavich $[26,27]$.

The kinetic method [11-13] was also used to probe the GBs of the peptides. During the deprotonation reaction studies, processes that were near thermoneutral formed proton-bound dimers. This was the only clustering reaction observed and it occurred for all amino acids and peptides studied. The dimer ions were produced and isolated by using the conditions outlined above. On-resonance collision-induced dissociation (CID) $[28,29]$ of the proton-bound dimer was performed under single collision conditions by varying center-of-mass collision energies from 0 to $75 \mathrm{eV}$ (maximum laboratory-frame energy of 0-525 eV). Argon was utilized as the collision gas at pressures of $(1-5) \times$ $10^{-7}$ torr. For dimers produced from a series of reference compounds of increasing basicity, the GB of a peptide was assigned at the point where the lowest energy CID product switched from being protonated peptide $\left(\mathrm{MH}^{+}\right)$to protonated reference base $\left(\mathrm{BH}^{+}\right)$. The kinetic method was also performed on the proton-bound dimer of histidine and lysine. This dimer was produced by FAB on a mixture of lysine and histidine in the glycerol matrix.

The FT-ICR cell was maintained at room temperature $(\sim 298 \mathrm{~K})$ during all experiments. All biomolecules were used as received from Sigma (St. Louis, MO) and Bachem Bioscience (Philadelphia, PA). Noncondensable gases were removed from the reference compounds by multiple freeze-pump-thaw cycles. 
Table 2. Reaction efficiencies for the proton transfer reactions of protonated amino acids and dipeptides with reference compounds

\begin{tabular}{|c|c|c|c|c|c|c|c|}
\hline \multirow[b]{2}{*}{ Reference compound } & \multirow[b]{2}{*}{$\mathrm{GB}^{\mathrm{b}}(\mathrm{kcal} / \mathrm{mol})$} & \multicolumn{6}{|c|}{ Reaction efficiencies ${ }^{\mathrm{D}}$} \\
\hline & & His & Lys & GlyHis & HisGly & GlyLys & LysGly \\
\hline Pyridine & 213.1 & 0.01 & - & - & - & - & - \\
\hline 3-Methylpyridine & 216.2 & 0.00 & 0.00 & - & - & - & - \\
\hline Diethylamine & 217.7 & 0.01 & 0.01 & - & - & - & - \\
\hline \multirow[t]{2}{*}{ Dipropylamine } & 219.7 & 0.04 & 0.05 & - & - & 0.04 & - \\
\hline & & Break $^{c}$ & Break $^{c}$ & & & & \\
\hline \multirow[t]{2}{*}{ 1-Methylpiperidine } & 221.9 & 0.14 & 0.16 & 0.03 & 0.04 & 0.05 & 0.01 \\
\hline & & & & & & Break $^{c}$ & \\
\hline \multirow[t]{2}{*}{ Triethylamine } & 224.5 & 0.89 & 1.15 & 0.03 & 0.02 & 0.13 & 0.02 \\
\hline & & & & Break $^{c}$ & Break $^{c}$ & & \\
\hline \multirow[t]{2}{*}{ Tripropylamine } & 226.2 & - & - & 0.18 & 0.13 & 0.36 & 0.06 \\
\hline & & & & & & & Break $^{c}$ \\
\hline$N, N$-Dimethylpropylamine & 229.4 & - & - & 0.33 & 0.34 & 0.62 & 0.39 \\
\hline $\begin{array}{c}N, N, N^{\prime}, N^{\prime} \text {-Tetramethyl- } \\
\text { 1, 3-diaminopropane }\end{array}$ & 231.0 & - & - & 0.80 & 0.86 & 0.86 & 0.76 \\
\hline
\end{tabular}

a The dash indicates that no experiment was performed.

${ }^{b}$ Reference compound gas-phase basicities were obtained from ref 14 .

'The break between slow and facile proton transfer for each amino acid or peptide.

\section{Results and Discussion}

The biomolecules examined in this study along with the reference compounds employed are listed in Tables 2 and 3 . Table 2 displays reaction efficiencies for histidine, lysine, and their dipeptides containing one glycine residue, while Table 3 displays the data for all six structural isomers of the tripeptides containing two glycine residues and one histidine or lysine residue. Assignments of GBs were made at a reaction efficiency of 0.10 ( $10 \%$ of collisions resulted in proton transfer) as the criterion to discern between an endoergic and exoergic reaction $[4,30]$. Table 4 lists the experimental GBs obtained for these compounds by proton transfer reactions and the kinetic method. The uncertainties were determined from the range of the bracketing reference compounds with an additional $2 \mathrm{kcal} / \mathrm{mol}$ included to account for uncertainties in the GBs of the reference compounds. The GBs of glycine, diglycine, and triglycine are listed for comparisons with previous work in this laboratory.

Typical deprotonation reaction spectra are shown in Figure 1. These spectra show the reaction of (GlyHis) $\mathrm{H}^{+}$with the reference compound tripropylamine (TPA) yielding a proton transfer rate constant of $2.19 \times 10^{-10} \mathrm{~cm}^{3} /$ molecule $\mathrm{s}^{-1}$ which translates into an efficiency of 0.18 . Figure 2 shows the isolation and dissociation of the proton-bound dimer consisting of triethylamine (TEA) and GlyHis (GlyHis $\cdot \mathrm{H} \cdot \mathrm{TEA})^{+}$ via the kinetic method. At low collision energies, the appearance of the predominant protonated GlyHis peak compared to the protonated TEA peak indicates

Table 3. Reaction efficiencies for the proton transfer reactions of protonated tripeptides with reference compounds

\begin{tabular}{|c|c|c|c|c|c|c|c|}
\hline \multirow[b]{2}{*}{ Reference compound } & \multirow[b]{2}{*}{$\mathrm{GB}^{\mathrm{a}}(\mathrm{kcal} / \mathrm{mol})$} & \multicolumn{6}{|c|}{ Reaction efficiencies } \\
\hline & & GlyGlyHis & GlyHisGly & HisGlyGly & GlyGlyLys & GlyLysGly & LysGlyGly \\
\hline 1-Methylpiperidine & 221.9 & 0.04 & 0.06 & 0.04 & 0.01 & 0.02 & 0.01 \\
\hline \multirow[t]{2}{*}{ Triethylamine } & 224.5 & 0.01 & 0.04 & 0.02 & 0.01 & 0.03 & 0.00 \\
\hline & & & Break $^{b}$ & & & Break $^{b}$ & \\
\hline \multirow[t]{2}{*}{ Tripropylamine } & 226.2 & 0.08 & 0.30 & 0.08 & 0.03 & 0.11 & 0.03 \\
\hline & & Break $^{\mathrm{b}}$ & & Break $^{b}$ & & & \\
\hline \multirow[t]{2}{*}{$N, N$-Dimethylpropylamine } & 229.4 & 0.34 & 0.53 & 0.37 & 0.02 & 0.55 & 0.03 \\
\hline & & & & & Break $^{b}$ & & Break $^{b}$ \\
\hline $\begin{array}{c}N, N, N^{\prime}, N^{\prime} \text {-Tetramethyl- } \\
\text { 1, 3-diaminopropane }\end{array}$ & 231.0 & 0.55 & 0.78 & 0.60 & 0.15 & 0.72 & 0.20 \\
\hline $\begin{array}{l}N, N, N^{\prime}, N^{\prime} \text {-Tetramethyl- } \\
\text { 1,4-diaminobutane }\end{array}$ & 232.6 & 1.09 & 1.28 & 1.17 & 0.95 & 1.08 & 1.01 \\
\hline
\end{tabular}

\footnotetext{
${ }^{\mathrm{a}}$ Reference compound gas-phase basicities were obtained from ref 14 .
}

${ }^{b}$ The break between slow and facile proton transfer for each peptide. 
Table 4. Experimental gas-phase basicities for glycine, histidine, lysine, and their di- and tripeptides

\begin{tabular}{lcc}
\hline & \multicolumn{2}{c}{$\mathrm{GB}^{\mathrm{a}}(\mathrm{kcal} / \mathrm{mol})$} \\
\cline { 2 - 3 } Compound & $\begin{array}{c}\text { Deprotonation } \\
\text { reaction method }\end{array}$ & $\begin{array}{c}\text { Kinetic } \\
\text { method }\end{array}$ \\
\hline \hline Glycine & $201.4 \pm 2.2^{\mathrm{b}}$ & $\mathrm{c}$ \\
GlyGly & $208.0 \pm 2.3^{\mathrm{b}}$ & $208.0 \pm 2.6^{\mathrm{d}}$ \\
GlyGlyGly & $219.7 \pm 3.1^{\mathrm{e}}$ & $221.0 \pm 2.6^{\mathrm{d}}$ \\
Histidine & $220.8 \pm 3.1$ & $223.2 \pm 3.2$ \\
Lysine & $220.8 \pm 3.1$ & $223.2 \pm 3.2$ \\
GlyLys & $223.2 \pm 3.3$ & $227.8 \pm 3.2$ \\
GlyHis & $225.3 \pm 2.8$ & $227.8 \pm 3.2$ \\
HisGly & $225.3 \pm 2.8$ & $227.8 \pm 3.2$ \\
GlyHisGly & $225.3 \pm 2.8$ & $226.2 \pm 3.2$ \\
GlyLysGly & $225.3 \pm 2.8$ & $227.8 \pm 3.2$ \\
GlyGlyHis & $226.5 \pm 3.6$ & $229.4 \pm 2.4$ \\
HisGlyGly & $226.5 \pm 3.6$ & $227.8 \pm 3.2$ \\
LysGly & $227.4 \pm 3.6$ & $227.8 \pm 3.2$ \\
GlyGlyLys & $230.7 \pm 2.8$ & $231.8 \pm 3.3$ \\
LysGlyGly & $230.7 \pm 2.8$ & $231.8 \pm 3.3$ \\
\hline
\end{tabular}

${ }^{a}$ All values adjusted to basicity scale of ref 14 .

${ }^{\mathrm{b}}$ From ref 5 .

${ }^{\circ}$ Glycine did not form a proton-bound dimer in ref 4

From ref 4.

${ }^{9}$ From ref 34

that, based on the kinetic method, GlyHis has a higher GB than TEA. (While the spectrum shown in Figure 2 was obtained with $E_{\mathrm{cm}}=17 \mathrm{eV}$, protonated GlyHis was also the major CID product at $E_{\mathrm{cm}}<17 \mathrm{eV}$.) The measured GB for GlyHis via the kinetic method is $227.8 \mathrm{kcal} / \mathrm{mol}$, while deprotonation reactions yielded a value of $225.3 \mathrm{kcal} / \mathrm{mol}$.

\section{Histidine and Lysine}

In this study, histidine and lysine are found to be of equivalent $\mathrm{GB}$ at $220.8 \mathrm{kcal} / \mathrm{mol}$ as determined by proton transfer reactions. These results are in general agreement with the work reported in Lias et al. [14], which found histidine to be more basic than lysine by $1.6 \mathrm{kcal} / \mathrm{mol}$. Our values are in opposition, however, to the laser-desorption studies conducted by Amster and co-workers [6] that show lysine to have a GB of 5.6 $\mathrm{kcal} / \mathrm{mol}$ higher than histidine (see Table 1). Our kinetic method studies also revealed histidine and lysine to have equivalent GBs at $223.2 \mathrm{kcal} / \mathrm{mol}$. This is in very good agreement with the values $224.8 \mathrm{kcal} / \mathrm{mol}$ for histidine and $224.3 \mathrm{kcal} / \mathrm{mol}$ for lysine as determined by Wu and Fenselau [16] by using the kinetic method.

We also applied the kinetic method to the protonbound dimer (His $\cdot \mathrm{H} \cdot$ Lys) ${ }^{+}$that was produced by FAB on a mixture of histidine and lysine. The results of this experiment are shown as a CID breakdown curve in Figure 3. At the energies studied, the only products are $\mathrm{LysH}^{+}$and $\mathrm{HisH}^{+}$. At near threshold center-of-mass collision energies from 0 to $1.5 \mathrm{eV}$, both
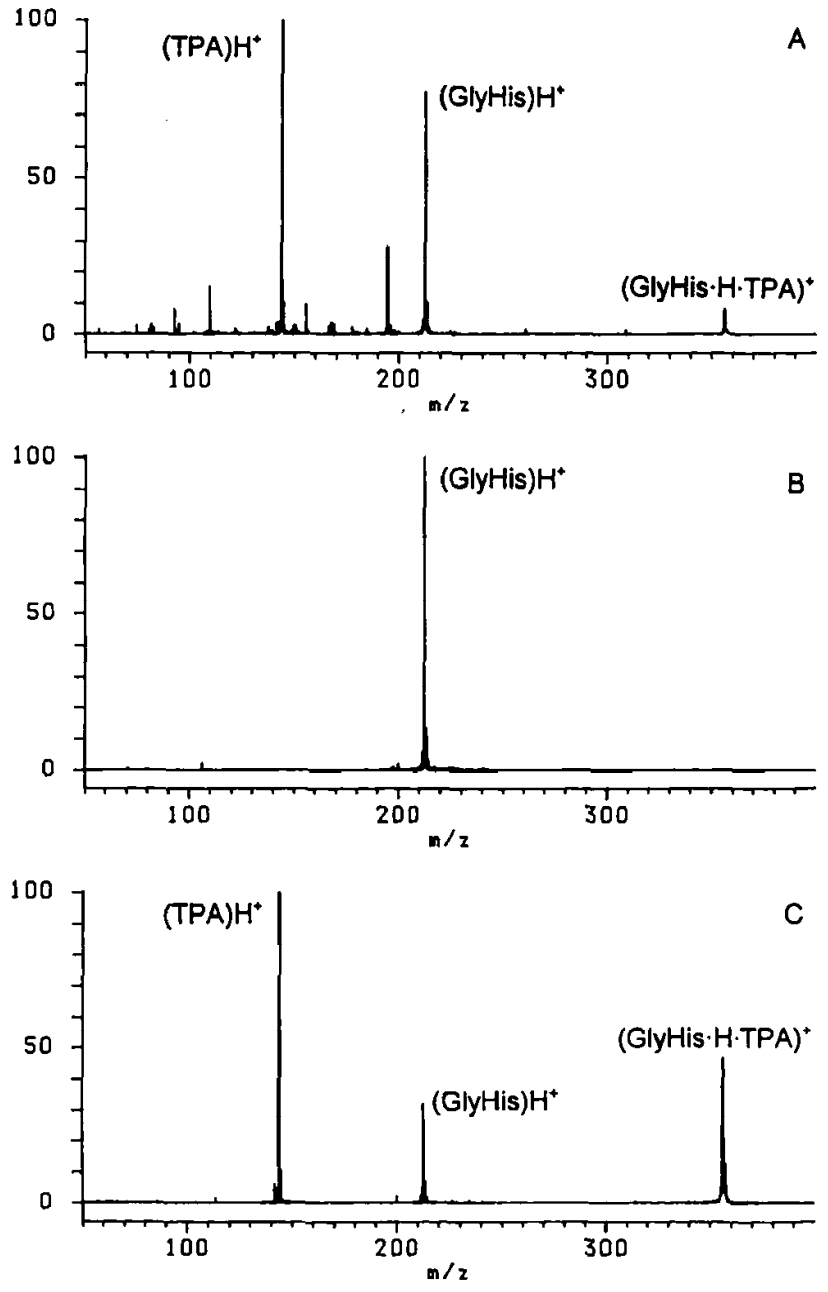

Figure 1. FT-ICR mass spectra for the reaction of (GlyHis) $\mathrm{H}^{+}$ with tripropylamine (TPA) at a static pressure of $4.9 \times 10^{-8}$ torr. (a) All ions produced by FAB on a solution of GlyHis in glycerol. (b) Isolation of (GlyHis) $\mathrm{H}^{+}$by swept frequency ejection techniques. (c) Reaction of (GlyHis) $\mathrm{H}^{+}$and TPA for $0.5 \mathrm{~s}$.

products form in equal intensities indicating near equivalent GBs for lysine and histidine. As the collision energy is increased above $1.5 \mathrm{eV}, \mathrm{HisH}^{+}$becomes the major CID product. In CID studies of proton-bound dimers, the more endoergic process begins to dominate (i.e., the less basic compound starts to retain the proton) as the collision energy is increased [4]; thus, lysine may be slightly more basic than histidine. Wu and Fenselau [16] also dissociated this dimer for kinetic method studies; they found near equivalent GBs but with histidine having a slightly higher $(0.5 \mathrm{kcal} / \mathrm{mol})$ basicity.

Amster and co-workers [3] previously suggested that the kinetic method and deprotonation reactions yield contradictory GBs for histidine and lysine. Our work that used both methods in the same laboratory does not support this conclusion. It should be noted, however, that while the experimental GB values reported by Amster were determined from proton transfer reactions of ions produced by laser desorption from 


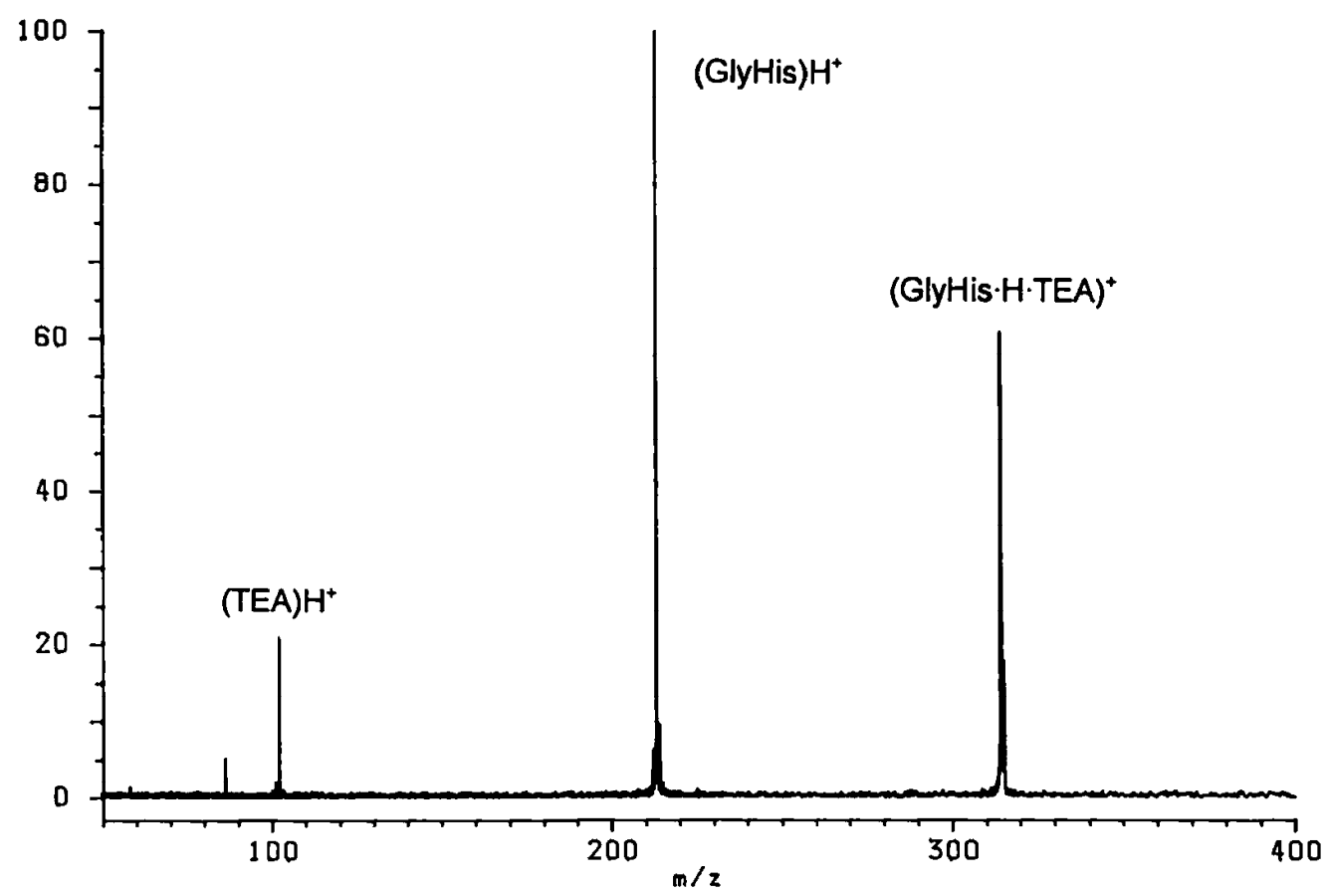

Figure 2. CID spectrum of (GlyHis $\cdot \mathrm{H} \cdot \mathrm{TEA})^{+}$with a center-of-mass collision energy of $17 \mathrm{eV}$. The triethylamine (TEA) pressure was $7.1 \times 10^{-8}$ torr, while the argon collision gas was maintained at $3.0 \times 10^{-7}$ torr.

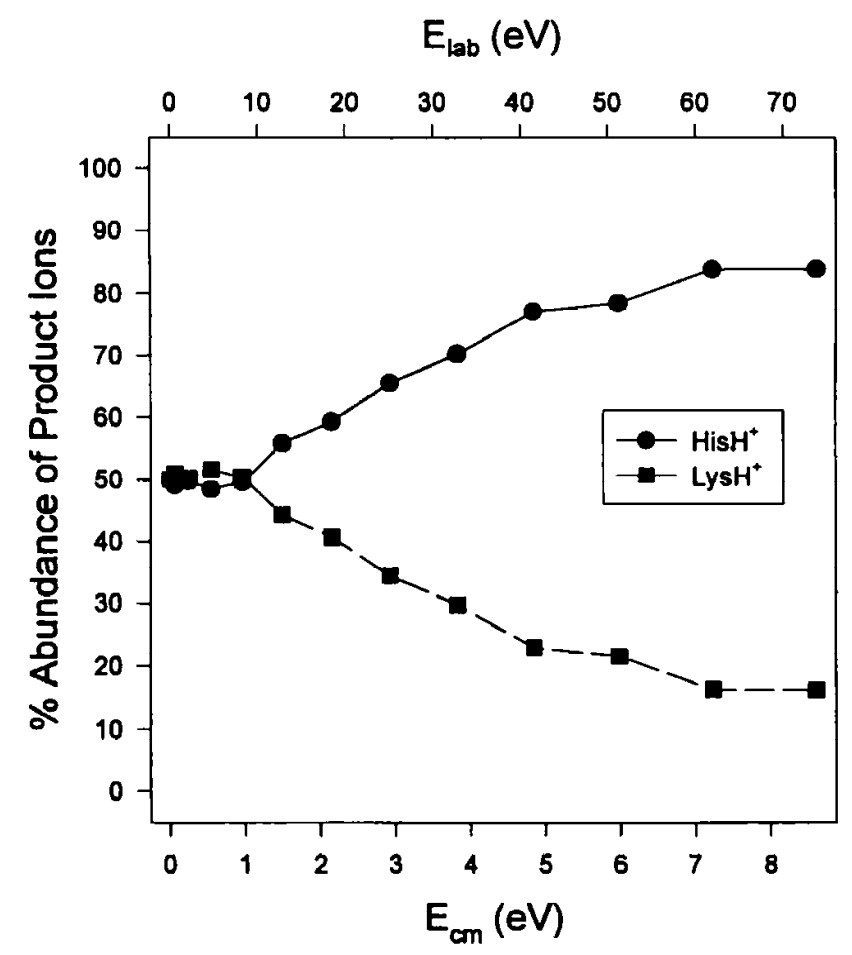

Figure 3. CID product ion abundances versus collision energy for the dissociation of the proton-bound dimer (His $\cdot \mathrm{H} \cdot \mathrm{Lys})^{+}$. $E_{\mathrm{cm}}$ (bottom scale) is the center-of-mass collision energy under single collision conditions, while $E_{\text {lab }}$ (top scale) refers to the maximum collision energy possible under these conditions. solid amino acids [3, 6], our ions were generated by FAB on a solution of the amino acid in glycerol. Whether the gas-phase ions produced from these two different sampling phases have the same structure is unknown. In addition, internal energy effects may contribute to the differences in measured GBs. Our ions were collisionally cooled prior to reaction, while those in the laser desorption work $[3,6]$ were not. Also, as can be seen in Table 1, the GB values from the Amster study are generally lower than those of other studies; their work was performed at an FT-ICR cell temperature of $\sim 350 \mathrm{~K}$, which may lower their measured GBs by about $2 \mathrm{kcal} / \mathrm{mol}$ relative to studies performed at $298 \mathrm{~K}$.

In solution, the side chain of histidine is clearly more acidic than that of lysine with $\mathrm{p} K_{a}$ values of 6.0 and 10.8, respectively [31], yet, in the gas phase the GBs of these amino acids appear to be equivalent. The uniqueness of these species relative to the other common amino acids (except arginine) is the structures of the side chains bearing nitrogen atoms that are available protonation sites. Glutamine and asparagine have amide groups present on their side chains, but the lone electron pair of the nitrogen is slightly delocalized into the carbonyl group making the amide group quite unreactive in solution [32]. This same effect can be inferred to occur in the gas phase resulting in a reduction of ability to be protonated at that site. Typtophan has a secondary amine located in a bulky indole ring, but the nitrogen of the amino group may not be able to form intramolecular hydrogen bonds easily due to steric hindrance. Thus, the GBs of glutamine, asparagine, and tryptophan have been shown to be lower 
than that of histidine and lysine $[2,8,14,15]$. The side chains of histidine and lysine have the ability to be protonated and then form intramolecular hydrogen bonds with the other heteroatoms present in the structure, such as the $N$-terminal nitrogen and the carbonyl oxygens. Previously, intramolecular hydrogen bonding was shown to increase the GBs of peptides [1, 4, 33-35]; this effect is discussed in the following sections.

The GBs of histidine and lysine are consistent with those of similar organic compounds. A chemical model for lysine (but lacking lysine's carboxyl group) is 1,5diaminopentane which has a GB of $223.0 \mathrm{kcal} / \mathrm{mol}$ [14]. This is $2.2 \mathrm{kcal} / \mathrm{mol}$ higher than the GB of lysine $(220.8 \mathrm{kcal} / \mathrm{mol})$ as determined by deprotonation reactions. This difference is within the experimental error and is also consistent with the effects on GB when an electron withdrawing carboxyl group is added alpha to an amino group. For example, the GBs of methylamine [14] and glycine [5] are 205.7 and $201.4 \mathrm{kcal} / \mathrm{mol}$, respectively; the GB of ethylamine [14] is 208.5 $\mathrm{kcal} / \mathrm{mol}$, while the GB of alanine [1] is $204.6 \mathrm{kcal} / \mathrm{mol}$. For histidine, the side chain is a 4-methyleneimidazolo group. The simplest organic model for this side chain is 4-methylimidazole, which has a GB of $216.6 \mathrm{kcal} / \mathrm{mol}$ [14]. With an n-ethylamino group attached to an imidazole ring at the 4-position [4(5)-2'-aminoethylimidazole (histamine)] the GB is $226.6 \mathrm{kcal} / \mathrm{mol}$ [36]. This GB is $5.8 \mathrm{kcal} / \mathrm{mol}$ higher than our GB of histidine $(220.8 \mathrm{kcal} / \mathrm{mol})$ as determined by deprotonation reactions. $\mathrm{Ab}$ initio calculations conducted by Hernández-Laguna et al. [36] showed that the most stable protonated form of histamine involves ring protonation with intramolecular hydrogen bonding between the amino group on the alkyl chain and the protonation site. The larger GB difference seen in the histidine/histamine model (as opposed to the lysine/1,5-diaminopentane model) suggests that the presence of a carboxyl group may have a greater effect on intramolecular hydrogen bonding in histidine than in lysine.

\section{Dipeptides}

Addition of a glycine residue to histidine or lysine to form dipeptides causes an increase in the GB. One reason for this is the additional inductive stabilization of the charge site by the glycine residues. Also, the stability of the protonated ions may be enhanced by the ability to form intramolecular hydrogen bonds within the di- and tripeptides. In comparison to the 7.6-kcal $/ \mathrm{mol} \mathrm{GB}$ increase of glycine going to diglycine [4], the GB increase is less pronounced when glycine forms a dipeptide with histidine at either terminus ( 4.5 $\mathrm{kcal} / \mathrm{mol}$ ). A $6.6-\mathrm{kcal} / \mathrm{mol}$ increase in GB is seen when a glycine residue is added to the $C$-terminus of lysine (see Table 4).

Examining the histidine-containing dipeptides, there is no detectable difference between the GBs of GlyHis and HisGly ( $225.3 \mathrm{kcal} / \mathrm{mol})$. Previous studies in our laboratory on less basic peptides have always revealed a difference in GB when comparing the two structural isomers of glycine and another amino acid. For example, the GB of AlaGly $(210.5 \mathrm{kcal} / \mathrm{mol})$ is higher than the GB of GlyAla $(209.4 \mathrm{kcal} / \mathrm{mol})$ by $1.1 \mathrm{kcal} / \mathrm{mol}$ [1], while the GB of SerGly $(210.6 \mathrm{kcal} / \mathrm{mol})$ is $1.3 \mathrm{kcal} / \mathrm{mol}$ higher than that of GlySer $(209.3 \mathrm{kcal} / \mathrm{mol})$ [5]. Also, Ewing et al. [37] determined the GB of ProGly (218.9 $\mathrm{kcal} / \mathrm{mol}$ ) to be $4.1 \mathrm{kcal} / \mathrm{mol}$ higher than the GB of GlyPro $(214.8 \mathrm{kcal} / \mathrm{mol})$. In addition, Gorman and Amster [38] observed this trend for several dipeptides that contain valine. For these dipeptides consisting of relatively low basicity acids (i.e., Gly, Ala, Ser, Pro), the presence of the most basic residue at the $N$ terminus increases the GB (relative to its presence at the $C$-terminus); this suggests the protonation site is at the $\mathrm{N}$-terminal amino group. The fact that the location of the histidine residue does not affect the GBs of HisGly and GlyHis suggests that the protonation site is on the side chain of histidine. This is consistent with $\mathrm{CID}$ studies of protonated larger peptides containing histidine (or lysine or arginine) that support side chain protonation on these residues [18-20].

For GlyHis and HisGly, the equivalence in GB as determined by deprotonation reactions and the kinetic method may also point to similar intramolecular hydrogen bonding. With the imino nitrogen on the imidazole ring being protonated, it can hydrogen bond with reasonable ease to any heteroatom in the dipeptide. Specifically, intramolecular hydrogen bonding between the protonated imino nitrogen and the terminal amine may be possible in both $\mathrm{GlyHisH}^{+}$and $\mathrm{HisGlyH}^{+}$as well as interaction with the carbonyl oxygens. If hydrogen bonding is similar in terms of both the heteroatoms involved and the bond distances, this may contribute to the near equivalent GBs of the two dipeptide structural isomers. It is interesting to note that the deprotonation reaction efficiencies for GlyHis and HisGly are equivalent within experimental error for each reference compound (see Table 2), again suggesting similarities in protonation site and structure.

The lysine dipeptides show more variation in GB with respect to position than the histidine dipeptides. Deprotonation reactions reveal that when the lysine residue is located on the $\mathrm{N}$-terminus (LysGly), the GB is noticeably higher than in GlyLys. In contrast, the kinetic method results indicate GlyLys and LysGly have equivalent GBs. The significantly larger GBs $(15-20 \mathrm{kcal} / \mathrm{mol})$ of the lysine dipeptides relative to the GB of GlyGly suggest that the proton is located on the $n$-butylamino group of lysine. If both of these dipeptides are protonated at the same site (i.e., the $n$-butylamino group), the deprotonation reaction data imply that different intramolecular hydrogen bonding is occurring as indicated by the differences in $G B$ for GlyLys $(223.2 \mathrm{kcal} / \mathrm{mol})$ and LysGly $(227.4 \mathrm{kcal} / \mathrm{mol})$. The $n$-butylamino side chain may have enough flexi- 
bility to interact with the $N$-terminus or carbonyl groups in either dipeptide to form an intramolecular hydrogen bond. Semiempirical calculations suggest that in lysine intramolecular hydrogen bonding occurs between the side chain $n$-butylamino group and the $N$-terminal amino group [3], but the location of hydrogen bonding in the dipeptides is unclear.

Investigations of other dipeptides containing lysine have been reported. By using proton transfer reactions, Gorman and Amster [38] determined that ValLys and LysVal have equivalent GBs of $218.0 \mathrm{kcal} / \mathrm{mol}$. These workers noted a general trend that the GB of the dipeptide was often equal to the GB of the most basic amino acid; this same group previously determined the GB of lysine to be $218.0 \mathrm{kcal} / \mathrm{mol}$ [6]. Our results from both deprotonation reactions and the kinetic method show not only a somewhat higher GB for lysine $(220.8 \mathrm{kcal} / \mathrm{mol})$, but also a significant increase in the GB of a dipeptide containing one lysine residue (relative to the GB of lysine alone). By using deprotonation reactions, there is also a $4.2-\mathrm{kcal} / \mathrm{mol}$ difference between the GBs obtained by deprotonation reactions for LysGly and GlyLys, while no difference was found between the GBs of LysVal and ValLys. One explanation for the valine/lysine dipeptide results may be steric hindrance from the isopropyl side chain of valine limiting the possible intramolecular hydrogen bond formations.

The kinetic method data suggest that GlyLys and LysGly have the same GB at $227.8 \mathrm{kcal} / \mathrm{mol}$. The kinetic method determination of the GB for these dipeptides falls between the reference compounds tripropylamine (TPA) and $N, N, N^{\prime}, N^{\prime}$-tetramethyl1,3-diaminopropane (TMP). Whereas in the deprotonation reactions GlyLys had already reacted with a high efficiency with triethylamine and TPA, it is not until TMP in the kinetic method that the proton is effectively retained by the reference compound. The reason for the difference between GBs obtained by deprotonation reactions and the kinetic method is unclear. One possibility is that for the dipeptides hydrogen bonding is occurring between the dipeptide and the reference compound in the dimer; this may impact the kinetic method results.

While lysine and histidine were found to have equivalent GBs, the presence of their residues in the dipeptides has different effects. One reason for this may be the differences in flexibility of the side chain structures. The histidine imino basic site on the imidazole ring has fewer degrees of freedom than the basic site on the lysine $n$-butylamino chain. Consequently, the likelihood of the protonation site repeatedly being in the same spatial region relative to an intramolecular hydrogen bonding site may be greater for a dipeptide containing histidine than for a similar dipeptide containing lysine.

Examining Table 2, there is a noticeable difference in reaction efficiencies between the amino acids and the dipeptides. With the amino acids, the proton trans- fer process is rapid when the reaction becomes exoergic. This is seen by the large increase in efficiency indicating the presence of an accessible route to the protonation site for the reference compound. The dipeptides show a more gradual increase in efficiency of proton transfer reactions. As discussed by Zhang et al. [4], this change in reactivity may be linked to multiple conformers having slightly different GBs. The number of conformational isomers, and thus the magnitude of this effect on reaction rates, will increase as the size of the peptide increases. In addition, steric hindrance may be limiting access of the reference compound to the protonation site $[4,9]$. Steric effects have been shown to lower rate constants in the deprotonation reactions of some bulky ions, such as tertbutylated pyridines [39], and several reports [4, 9, 40] suggest that this also occurs in the reactions of small peptides. Again, this effect would increase as the peptide size increases.

\section{Tripeptides}

A trend is evident for the tripeptides formed upon incorporation of a second glycine residue. Not only is there an increase in GB, but also near equivalent reaction efficiencies and GBs are seen when the basic amino acid is placed at either the $\mathrm{N}$ - or $\mathrm{C}$-terminus of the tripeptide. The tripeptides with the basic residue in the middle undergo more facile deprotonation, which may suggest that intramolecular hydrogen bonding is more hindered for a middle residue than a terminal residue. $\mathrm{Ab}$ initio calculations on protonated triglycine have revealed large ring interactions (involving all three residues) via intramolecular hydrogen bonding [34]. When the protonation site is located in the middle of the tripeptide, intramolecular hydrogen bonding encompassing all three residues cannot occur. The result may be weaker hydrogen bonding and a lower basicity relative to tripeptide containing a terminal histidine or lysine residue.

If the residue of interest is less basic than histidine or lysine, the reaction efficiencies of the tripeptides do not follow the same trend as noted in the preceding text. For example, with GlyGlyAla and GlyAlaGly [1], the GBs and deprotonation reaction efficiencies are similar; this is also true for GlyGlyPro and GlyProGly [37]. However, when the amino acid is on the $N$ terminus (i.e., AlaGlyGly or ProGlyGly) the tripeptide deprotonates more slowly than the preceding tripeptides and therefore is assigned a higher GB. Wu and Fenselau [41] also noted this difference in kinetic method studies of GlyGlyAla $(216.3 \mathrm{kcal} / \mathrm{mol})$ and AlaGlyGly $(217.1 \mathrm{kcal} / \mathrm{mol})$. The foregoing observations point to protonation of the $\mathrm{N}$-terminal amino group for these less basic tripeptides. In turn, since lysine- and histidine-containing tripeptides do not behave in this manner, the implication is protonation of the basic side chain. 
In this study, although histidine and lysine were found to be of equivalent basicity, tripeptides that incorporate lysine are generally more basic than the corresponding tripeptides containing histidine. The lysine residue may participate to a greater extent in intramolecular hydrogen bonding with the results being higher GBs for lysine-containing peptides. For example, when the basic residue is located on either terminus, histidine-containing tripeptides have GBs of $226.5 \mathrm{kcal} / \mathrm{mol}$, but if the terminal residue is lysine, the GBs are $230.7 \mathrm{kcal} / \mathrm{mol}$.

The kinetic method revealed a GB of $229.4 \mathrm{kcal} / \mathrm{mol}$ for HisGlyGly which is in excellent agreement with the value of $230.0 \mathrm{kcal} / \mathrm{mol}$ determined by $\mathrm{Wu}$ and Fenselau [41]. Our deprotonation reactions show GlyHisGly to have the same GB as GlyLysGly at $225.3 \mathrm{kcal} / \mathrm{mol}$. In our kinetic method studies, GlyHisGly (226.2 $\mathrm{kcal} / \mathrm{mol}$ ) is seen to have a slightly lower GB compared to GlyLysGly $(227.8 \mathrm{kcal} / \mathrm{mol})$, while $\mathrm{Wu}$ and Fenselau [16] found GlyHisGly to possess a slightly higher GB than GlyLysGly. This minor discrepancy is within the experimental errors of the two studies and is reasonable considering the size and flexibility of the structures involved.

\section{Conclusions}

Deprotonation reactions and the kinetic method have been carried out in a FT-ICR mass spectrometer to determine the gas-phase basicities of histidine, lysine, and their selected di- and tripeptides. The GB values determined by the two methods generally differ by less than $2.5 \mathrm{kcal} / \mathrm{mol}$. The data suggest that the side chains of these basic residues are protonated when they are incorporated into a peptide. The location of the protonated residue may affect the GBs of peptide structural isomers by varying the amount of intramolecular hydrogen bonding involved in the ion.

\section{Acknowledgments}

The authors thank the National Institutes of Health (R15GM47657-01A1) and the Ohio Board of Regents Academic Challenge Program for financial support.

\section{References}

1. Cassady, C. J.; Carr, S. R.; Zhang, K.; Chung-Phillips, A. J. Org. Chem. 1995, 60, 1704-1712.

2. Bojesen, G. I. Am. Chem. Soc. 1987, 109, 5557-5558.

3. Bliznyuk, A. A.; Schaefer, H. F.; Amster, I. J. J. Am. Chem. Soc. 1993, 115, 5149-5154.

4. Zhang, K.; Zimmerman, D. M.; Chung-Phillips, A.; Cassady, C. J. J. Am. Chem. Soc. 1993, 115, 10812-10822.

5. McKiernan, J. W.; Beltrame, C. E. A.; Cassady, C. J. J. Am. Soc. Mass Spectrom. 1994, 5, 718-723.

6. Gorman, G. S.; Speir, J. P.; Turner, C. A.; Amster, I. J. J. Am. Chem. Soc. 1992, 114, 3986-3988.

7. Li, X.; Harrison, A. G. Org. Mass Spectrom. 1993, 28, 366-371.
8. Wu, Z.; Fenselau, C. Rapid Commun. Mass Spectrom. 1992, 6, 403-405.

9. Wu, J.; Gard, E.; Bregar, J.; Green, M. K.; Lebrilla, C. B. I. Am. Chem. Soc. 1995, 117, 9900-9905.

10. Caldin, E.; Gold, V. Proton-Transfer Reactions; Wiley: New York, 1975.

11. Cooks, R. G.; Patrick, J. S.; Kotiaho, T.; McLuckey, S. A. Mass Spectrom. Rev. 1994, 13, 287-339.

12. Cooks, R. G.; Kruger, T. L. I. Am. Chem. Soc. 1977, 99, 1279-1281.

13. McLuckey, S. A.; Cameron, D.; Cooks, R. G. J. Am. Chem. Soc. 1981, 103, 1313-1317.

14. Lias, S. G.; Liebman, J. F.; Levin, R. D. J. Phys. Chem. Ref. Data 1984, 13, 696-808. This is a compilation of gas-phase basicity data with histidine and lysine data attributed to otherwise unpublished results of $M$. J. Locke and R. T. McIver.

15. Isa, K.; Omote, T.; Amaya, M. Org. Mass Spectrom. 1990, 25, 620-628.

16. Wu, Z.; Fenselau, C. Rapid Commun. Mass Spectrom. 1994, 8, 777-780.

17. Bojesen, G.; Breindahl, T. I. Chem. Soc. Perkin Trans. 2 1994, 1029-1037.

18. Johnson, R. S.; Martin, S. A.; Biemann, K. Int. J. Mass Spectrom. Ion Processes 1988, 86, 137-154.

19. Morgan, D. G.; Bursey, M. M. J. Mass Spectrom. 1995, 30, 290-295.

20. Morgan, D. G.; Bursey, M. M. Org. Mass Spectrom. 1994, 29, 354-359.

21. Perel, J.; Faull, K.; Mahoney, J. F.; Tyler, A. N.; Barchas, J. D. Am. Lab. 1984, 16, 94-100.

22. Ahmed, M. S.; Dunbar, R. C. I. Am. Chem. Soc. 1987, 109, 3215-3219.

23. Comisarow, M. B.; Grassi, V.; Parisod, G. I. Chem. Phys. 1978, 57, 413-416.

24. Espenson, J. H. Chemical Kinetics and Reaction Mechanisms; McGraw-Hill: New York, 1981.

25. Bartmess, J. E.; Georgiadis, R. M. Vacuum 1983, 33, 149-153.

26. Su, T.; Chesnavich, W. J. I. Chem. Phys. 1982, 76, 5183-5185.

27. Su, T. J. Chem. Phys. 1988, 88, 5355.

28. Cody, R. B.; Freiser, B. S. Int. J. Mass Spectrom. Ion Phys. 1982, 41, 199-204.

29. Bumier, R. C.; Cody, R. B.; Freiser, B. S. J. Am. Chem. Soc. 1982, 104, 7436-7441.

30. Büker, H.-H.; Grützmacher, H.-F. Int. I. Mass Spectrom. Ion Processes 1991, 109, 95-104.

31. Voet, D; Voet, J. Biochemistry; Wiley: New York, 1990.

32. Vollhardt, K. P. C. Organic Chentistry; W. H. Freeman: New York, 1987.

33. Campbell, S.; Beauchamp, J. L.; Rempe, M.; Lichtenberger, D. L. Int. I. Mass Spectrom. Ion Processes 1992, 117, 83-99.

34. Zhang, K.; Cassady, C. J.; Chung-Phillips, A. I. Am. Chem. Soc, 1994, 116, 11512-11521.

35. Wu, J.; Lebrilla, C. B. J. Am. Chem. Soc. 1993, 115, 3270-3275.

36. Hernández-Laguna, A.; Abboud, J.-L. M.; Notario, R.; Homan, H.; Smeyers, Y. G. J. Am. Chem. Soc. 1993, 115, 1450-1454.

37. Ewing, N. P.; Zhang, X.; Cassady, C. J. J. Mass Spectrom., in press.

38. Gorman, S.; Amster, I. J. J. Am. Chem. Soc. 1993, 115, 5729-5735.

39. Meot-Ner, M.; Smith, J. C. I. Am. Chem. Soc 1991, 113, 862-869.

40. Wu, J.; Lebrilla, C. B. I. Am. Soc. Mass Spectrom. 1994, 6, 91-101.

41. Wu, Z.; Fenselau, C. Tetrahedron 1993, 41, 9197-9206. 